\title{
Successful chemotherapy with carboplatin and nab-paclitaxel for thymic large cell neuroendocrine carcinoma: A case report
}

\author{
SATOSHI IGAWA ${ }^{1}$, NOBUYUKI YANAGISAWA ${ }^{2}$, HIDEYUKI NIWA ${ }^{1}$, MIKIKO ISHIHARA $^{1}$, YASUHIRO HIYOSHI ${ }^{1}$, \\ SAKIKO OTANI $^{1}$, KEN KATONO $^{1}$, JIICHIRO SASAKI $^{3}$, YUKITOSHI SATOH $^{4}$ and NORIYUKI MASUDA ${ }^{1}$ \\ Departments of ${ }^{1}$ Respiratory Medicine and ${ }^{2}$ Pathology; ${ }^{3}$ Research and Development Center for New Medical Frontiers; \\ ${ }^{4}$ Department of Thoracic Surgery, Kitasato University School of Medicine, Sagamihara, Kanagawa 252-0374, Japan
}

Received December 14, 2014; Accepted July 30, 2015

DOI: $10.3892 / 01.2015 .3812$

\begin{abstract}
Thymic large cell neuroendocrine carcinomas (LCNECs) are rare, and the optimal regimen for second and subsequent lines of chemotherapy for the treatment of LCNECs remains unknown. In the present case study, a 59-year-old male with post-operative recurrent thymic LCNEC was treated with nab-paclitaxel and carboplatin every 4 weeks as third-line chemotherapy, and a partial response was achieved following 4 cycles of this regimen. The patient developed grade 4 neutropenia and grade 3 leukopenia, but none of the other toxicities, including peripheral neuropathy, were severe. Therefore, the patient was able to tolerate this salvage chemotherapy. To the best of our knowledge, the present study is the first case demonstrating clinically meaningful antitumor activity by combination chemotherapy with carboplatin and nab-paclitaxel, resulting in a positive response in a patient with thymic LCNEC.
\end{abstract}

\section{Introduction}

Thymic carcinomas are rare invasive neoplasms, and their clinical course tends to be more aggressive than that of thymomas (1-3). The World Health Organization has established a thymic epithelial tumor classification criteria, according to which, neuroendocrine carcinoma (NEC) is classified as a subtype of thymic carcinoma, and LCNEC is classified under thymic NEC as a pulmonary neuroendocrine tumor (4). Thymic NECs are relatively rare neoplasms that account for only $2-4 \%$ of all anterior mediastinal neoplasms (5) Due to this low frequency rate, no standard chemotherapy has been established for thymic LCNEC following failure of initial chemotherapy, which has been recognized as effective against high-grade NEC. Ogawa et al (6) previously reported the case

Correspondence to: Dr Satoshi Igawa, Department of Respiratory Medicine, Kitasato University School of Medicine, 1-15-1 Kitasato, Minami, Sagamihara, Kanagawa 252-0374, Japan

E-mail: igawa@kitasato-u.ac.jp

Key words: thymic large cell neuroendocrine carcinoma, chemotherapy, carboplatin, nab-paclitaxel of a patient with primary thymic LCNEC. The patient received a curative thymectomy and subsequent successful adjuvant chemotherapy. In the present study, a case of chemorefractory thymic LCNEC that exhibited a good response to carboplatin and nab-paclitaxel combination chemotherapy as a salvage therapy is reported. Written informed consent was obtained from the patient.

\section{Case report}

A 59-year-old male was admitted to the Kitasato University Hospital (Sagamihara, Japan) in April 2009 for further examination and treatment following the identification of an abnormal shadow on a regular health check-up chest X-ray. Following the differential diagnosis of thymic carcinoma, the patient underwent a total thymectomy. The elastic soft tumor was surrounded by thymic fat tissue and measured 40x35x28 mm. Histologically, the tumor displayed thick trabeculae with irregular nests separated by fibrovascular stroma and scattered abortive rosette-like structures (Fig. 1A). The tumor cells were large, oval-to-polygonal in shape and contained eosinophilic granular cytoplasm. The nuclear chromatin was granular, and the nucleoli were not clearly visible. Small foci of coagulation necrosis were also observed (Fig. 1B). The average mitotic count was high (30/10 high-power fields; Fig. 1C), and the Ki-67 indices ranged from 20 to $30 \%$, according to MIB-1 staining. Immunohistochemically, the tumor cells were diffusely positive for chromogranin A, synaptophysin and neural cell adhesion molecule (Fig. 2), confirming their neuroendocrine nature. These pathological findings were consistent with thymic LCNEC.

The patient was treated with 3 courses (4-week cycles) of adjuvant chemotherapy, based on a platinum doublet using a cisplatin $\left(60 \mathrm{mg} / \mathrm{m}^{2}\right.$, day 1$)$ and irinotecan $\left(\mathrm{IP} ; 60 \mathrm{mg} / \mathrm{m}^{2}\right.$, days1, 8 and 15) regimen. The patient survived without recurrence for 3 years following total thymectomy. However, computed tomography (CT) of the chest 4 years later revealed right pleural dissemination and metastasis in a right mediastinal and a right hilar lymph node. The patient was treated with 2 courses (3-week cycles) of amrubicin (AMR; $40 \mathrm{mg} / \mathrm{m}^{2}$, days 1-3) monotherapy, and subsequently re-challenged with 2 courses of the aforementioned IP regimen, but control of the disease was not achieved (Fig. 3A). 

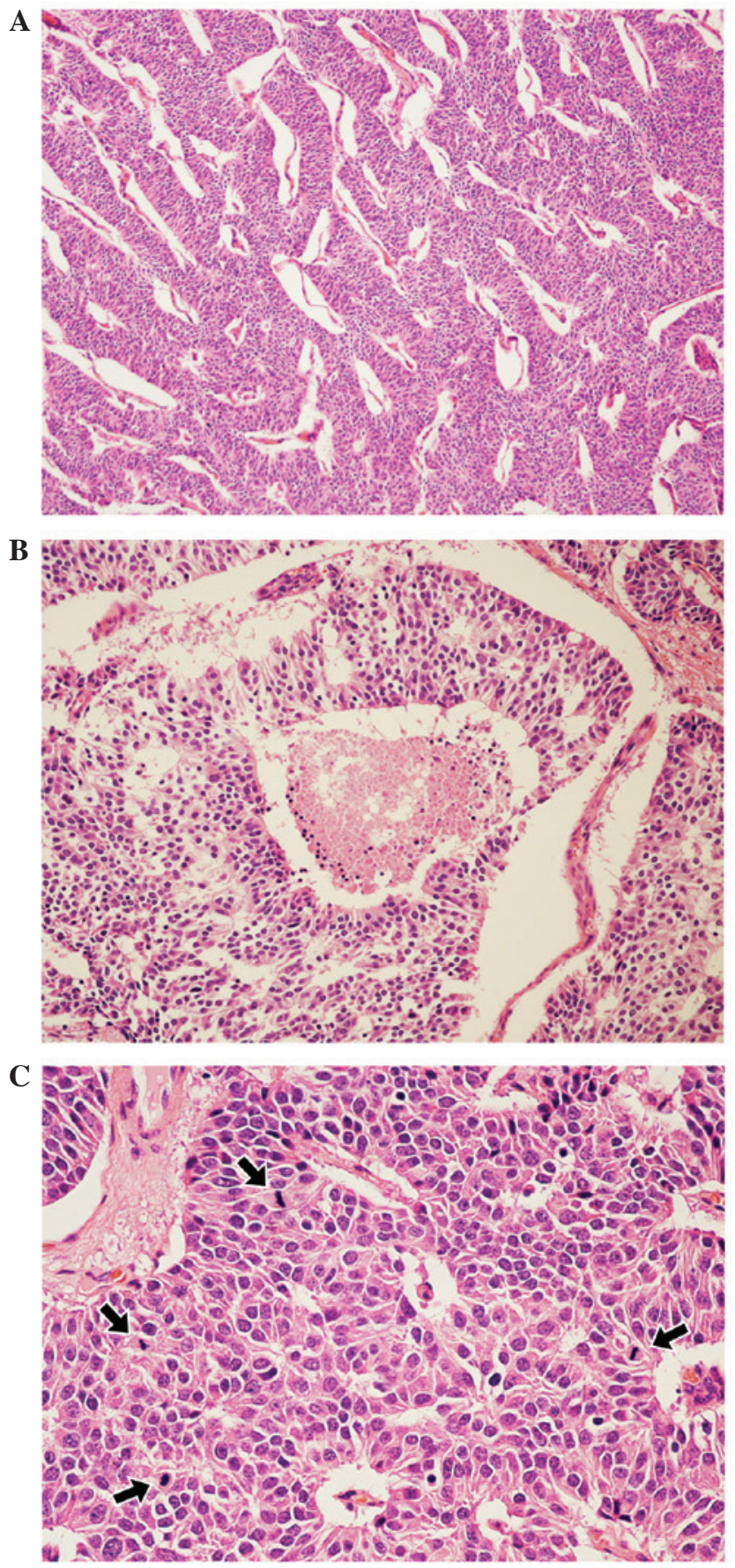

Figure 1. Hematoxylin and eosin staining. (A) The tumor presented with thick trabeculae with irregular nests separated by fibrovascular stroma, and scattered rosette-like structures (magnification, x100). (B) Small foci of coagulation necrosis were also observed (magnification, x100). (C) The tumor cells exhibited high mitotic indices (arrows; magnification, x400).

Since the performance status of the patient and the function of the major organs were good in June 2014, it was possible to treat the patient with a salvage chemotherapy regimen consisting of weekly nab-paclitaxel infusion $\left(100 \mathrm{mg} / \mathrm{m}^{2}\right)$ plus carboplatin, at an area under the curve of 6 , every 4 weeks. CT scans of the chest following 2 cycles of this regimen revealed a $32 \%$ reduction in the sum of the diameters of the target lesions compared with the baseline, indicating a partial response (Fig. 3B). A reduction in the size of each of the target lesions was confirmed following 4 cycles

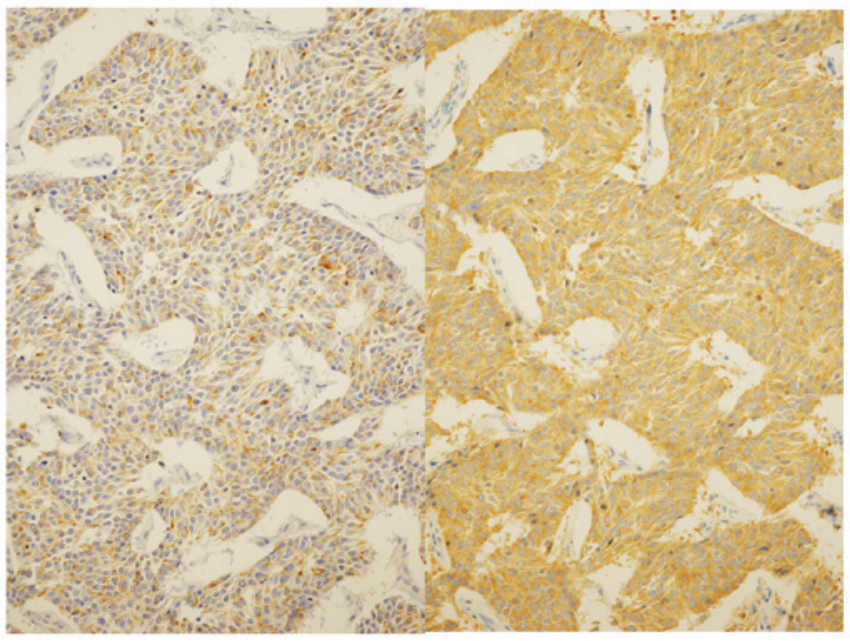

Figure 2. Immunohistochemically, the tumor cells were diffusely positive for chromogranin A (left) and synaptophysin (right) (magnification, x200).

of this regimen in October 2014 (Fig. 3C). The response was evaluated according to the Response Evaluation Criteria in Solid Tumors, version 1.1 (7). Additionally, the levels of serum NSE, which had increased to $21.2 \mathrm{ng} / \mathrm{ml}$ (exceeding the institutional upper limit of the normal values, $<16.3 \mathrm{ng} / \mathrm{ml}$ ) prior to the treatment, were reduced to $7.0 \mathrm{ng} / \mathrm{ml}$ following 4 cycles of this regimen.

The toxicity profile, reported as the highest toxicity grades during all the cycles of this regimen, was as follows: Hematological toxicity in the form of grade 4 neutropenia, grade 2 leukopenia and grade 1 thrombocytopenia; and non-hematological toxicity in the form of grade 1 sensory neuropathy, arthralgia, nausea and alopecia. Due to neutropenia, the patient was unable to receive nab-paclitaxel on day 15 of the second and fourth cycles of the regimen, although no dose reduction was required. Follow-up examinations are performed every 8 weeks and at present, the patient remains well with a partial response status.

\section{Discussion}

Thymic LCNECs are rare, and their optimal treatment remains unclear. The results obtained in the present case suggest that nab-paclitaxel combined with carboplatin may be an effective treatment for thymic LCNEC. To the best of our knowledge, the present study is the first case demonstrating the efficacy of the aforementioned regimen as a treatment for thymic LCNEC. A previous global phase III study observed that weekly administration of nab-paclitaxel plus carboplatin yielded a significantly higher overall response rate compared with solvent-based paclitaxel plus carboplatin in patients with non-small cell lung cancer (NSCLC) (8). Nab-paclitaxel, a $130-\mathrm{nm}$ albumin-bound paclitaxel formulation, is a promising novel agent for the treatment of NSCLC, and breast and gastric cancer $(9,10)$. A previous preclinical study reported that nab-paclitaxel exhibited greater antitumor activity than equitoxic doses of Cremophor-based paclitaxel in xenograft models of lung (H522), breast (MX-1), ovarian (SK-OV-3), prostate (PC-3) and colon (HT29) human tumors (11). The same study reported that the intratumor concentration of paclitaxel in the 
A
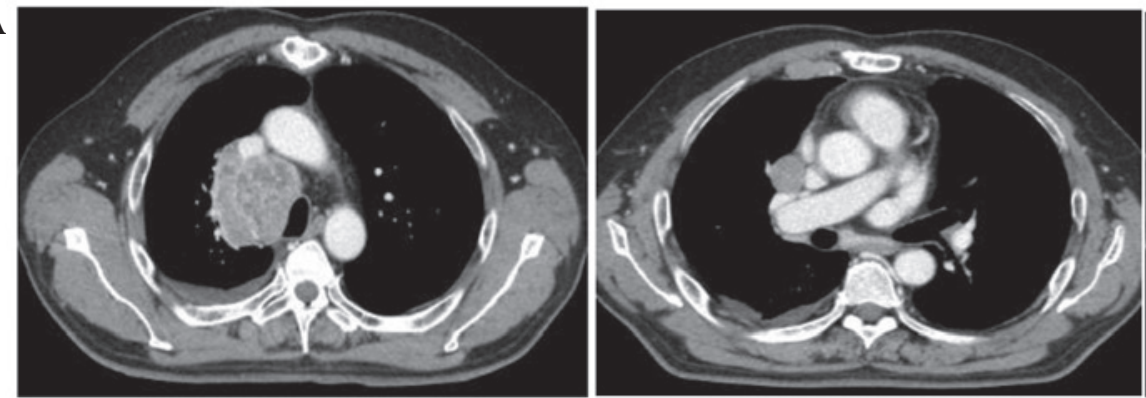

B

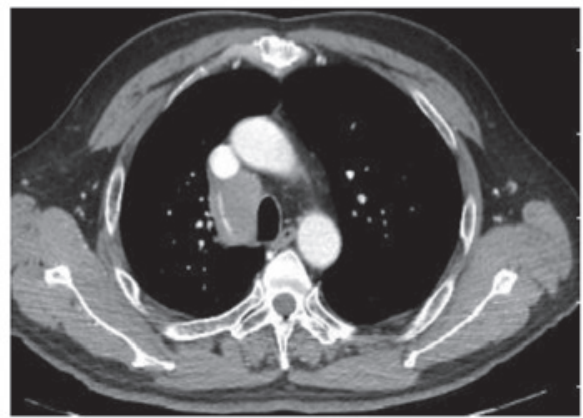

C

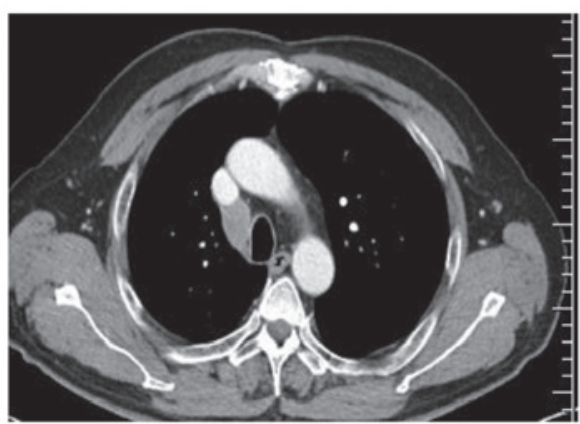

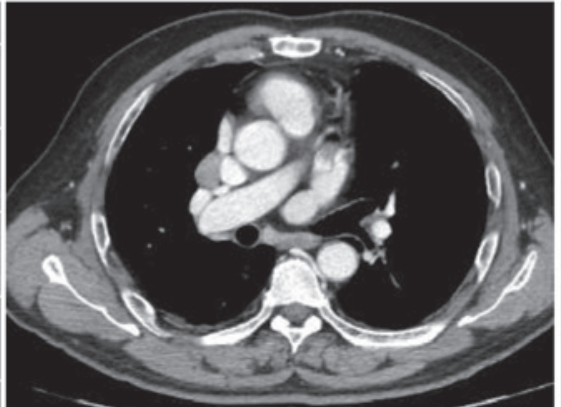

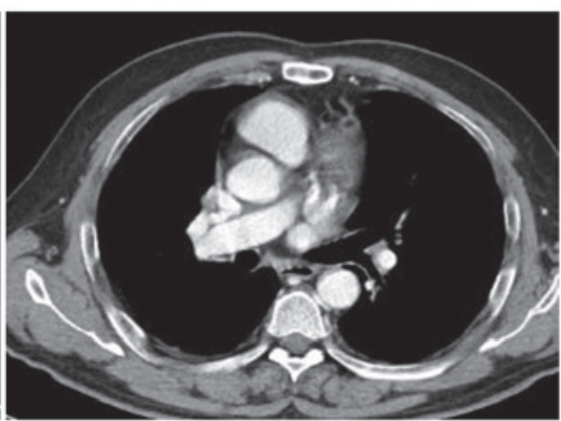

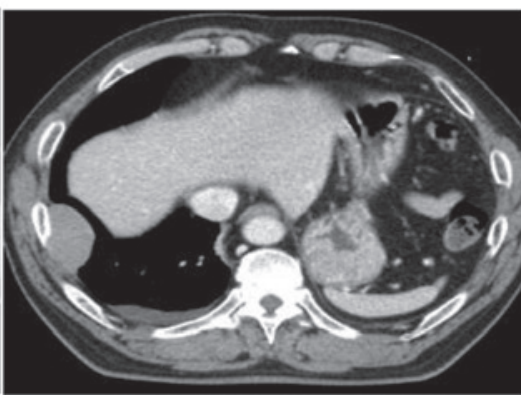
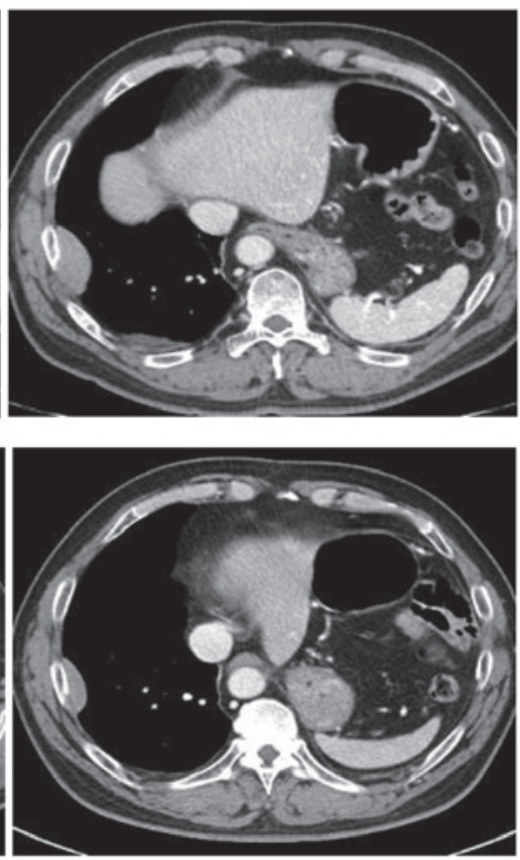

Figure 3. Chest computed tomography (A) prior to chemotherapy, and following (B) 2 and (C) 4 cycles of nab-paclitaxel plus carboplatin combination chemotherapy. (A-C) Right pleural dissemination (right) and metastasis in a right mediastinal (left) and a right hilar lymph node (centre) was observed. (B and C) The size of the metastatic lesions was reduced following chemotherapy.

MX-1 xenograft model was 33\% higher following administration of nab-paclitaxel compared with after administration of equal doses of Cremophor-based paclitaxel. These findings were supported by the 9.9- and 4.2-fold increases observed in endothelial cell binding and transcytosis, respectively, for nab-paclitaxel compared with Cremophor-based paclitaxel (11).

Previous studies have indicated that solvent-based paclitaxel plus carboplatin and carboplatin plus AMR are effective treatments for unresectable thymic carcinoma. Therefore, carboplatin-based, cisplatin, doxorubicin, vincristine and cyclophosphamide, and cisplatin, vincristine, doxorubicin and etoposide regimens may be suitable treatment options for patients with thymic LCNECs (12-17). However, the optimal regimen for second or subsequent lines of chemotherapy for the treatment of thymic carcinoma remains unclear. Etoposide plus cisplatin, IP and AMR monotherapy have been demonstrated to be particularly effective in SCLC (18-20). A previous study indicated that solvent-based paclitaxel plus carboplatin may be active in SCLC that is refractory to the above-based regimens (21). Previous studies have reported that the clinical behavior and prognosis of LCNEC are similar to those of SCLC, and that SCLC-based regimens are effective in patients with LCNEC $(22,23)$. Therefore, it appears to be reasonable to conclude that nab-paclitaxel combined with carboplatin is a useful option for the treatment of thymic LCNEC that is refractory to SCLC-based regimens. Further studies regarding the use of this regimen for the treatment of thymic LCNEC are required.

\section{References}

1. Shimosato Y, Kameya T, Nagai K and Suemasu K: Squamous cell carcinoma of the thymus: An analysis of eight cases. Am J Surg Pathol 1: 109-121, 1977.

2. Suster S and Rosai J: Thymic carcinoma. A clinicopathologic study of 60 cases. Cancer 67: 1025-1032, 1991.

3. Yano M, Sasaki H, Yokoyama T, Yukiue H, Kawano O, Suzuki S and Fujii Y: Thymic carcinoma 30 cases at a single institution. J Thorac Oncol 3: 265-269, 2008.

4. Marx A, Shimosato Y, Kuo TT, et al: Thymic neuroendocrine tumours. In: World Health Organization Classification of Tumours. Pathology and genetics of tumors of the Lung, Pleura, Thymus and Heart. Travis WD, Brambilla E, Muller-Hermelink HK and Harris CC (eds.). IARC Press, Lyon, pp188-195, 2004.

5. Wick MR and Rosai J: Neuroendocrine neoplasms of the mediastinum. Semin Diagn Pathol 8: 35-51, 1991.

6. Ogawa F, Iyoda A, Amano H, Nezu K, Jiang SX, Okayasu I and Satoh Y: Thymic large cell neuroendocrine carcinoma: Report of a resected case - a case report. J Cardiothorac Surg 5: 115, 2010.

7. Eisenhauer EA, Therasse P, Bogaerts J, et al: New response evaluation criteria in solid tumours: Revised RECIST guideline (version 1.1). Eur J Cancer 45: 228-247, 2009. 
8. Socinski MA, Bondarenko I, Karaseva NA, Makhson AM, Vynnychenko I, Okamoto I, Hon JK, Hirsh V, Bhar P, Zhang $\mathrm{H}$, et al: Weekly nab-paclitaxel in combination with carboplatin versus solvent-based paclitaxel plus carboplatin as first-line therapy in patients with advanced non-small-cell lung cancer: Final results of a phase III trial. J Clin Oncol 30: 2055-2062, 2012.

9. Koizumi W, Morita S and Sakata Y: A randomized phase III trial of weekly or 3-weekly doses of nab-paclitaxel versus weekly doses of Cremophor-based paclitaxel in patients with previously treated advanced gastric cancer (ABSOLUTE Trial). Jpn J Clin Oncol 45: 303-306, 2015.

10. Chirgwin J and Chua SL: Management of breast cancer with nanoparticle albumin-bound (nab)-paclitaxel combination regimens: A clinical review. Breast 20: 394-406, 2011.

11. Desai N, Trieu V, Yao Z, Louie L, Ci S, Yang A, Tao C, De T, Beals B, Dykes D, et al: Increased antitumor activity, intratumor paclitaxel concentrations, and endothelial cell transport of cremophor-free, albumin-bound paclitaxel, ABI-007, compared with cremophor-based paclitaxel. Clin Cancer Res 12: 1317-1324, 2006.

12. Lemma GL, Lee JW, Aisner SC, Langer CJ, Tester WJ, Johnson DH and Loehrer PJ Sr: Phase II study of carboplatin and paclitaxel in advanced thymoma and thymic carcinoma. J Clin Oncol 29: 2060-2065, 2011.

13. Igawa S, Murakami H, Takahashi T, Nakamura Y, Tsuya A, Naito T, Kaira K, Ono A, Shukuya T, Tamiya A, et al: Efficacy of chemotherapy with carboplatin and paclitaxel for unresectable thymic carcinoma. Lung Cancer 67: 194-197, 2010.

14. Takeda K, Hirai F, Yamanaka T, Taguchi K, Daga H, Shimizu J, Kogure Y, Kimura T, Tanaka K, Iwamoto Y, et al: A multicenter prospective study of carboplatin and paclitaxel for advanced thymic carcinoma: West Japan Oncology Group 4207L. ASCO Annual Meeting Abstracts. J Clin Oncol (Suppl) 31: 7529, 2013.

15. Kawashima Y, Inoue A, Sugawara S, Harada M, Kobayashi K, Kozuki T, Kuyama S, Sakakibara T, Maemondo M, Asahina $\mathrm{H}$, et al: Phase II study of amrubicin (AMR) and carboplatin (CBDCA) for invasive thymoma (IT) and thymic carcinoma (TC): NJLCG0803. ASCO Annual Meeting Abstracts. J Clin Oncol (Suppl) 31: 7530, 2013.
16. Yoh K, Goto K, Ishii G, Niho S, Ohmatsu H, Kubota K, Kakinuma R, Nagai K, Suga $M$ and Nishiwaki Y: Weekly chemotherapy with cisplatin, vincristine, doxorubicin, and etoposide is an effective treatment for advanced thymic carcinoma. Cancer 98: 926-931, 2003.

17. Agatsuma T, Koizumi T, Kanda S, Ito M, Urushihata K, Yamamoto H, Hanaoka M and Kubo K: Combination chemotherapy with doxorubicin, vincristine, cyclophosphamide, and platinum compounds for advanced thymic carcinoma. J Thorac Oncol 6: 2130-2134, 2011.

18. Jackman DM and Johnson BE: Small-cell lung cancer. Lancet 366: 1385-1396, 2005.

19. Onoda S, Masuda N, Seto T, Eguchi K, Takiguchi Y, Isobe H, Okamoto H, Ogura T, Yokoyama A, Seki N, et al; Thoracic Oncology Research Group Study 0301: Phase II trial of amrubicin for treatment of refractory or relapsed small-cell lung cancer: Thoracic Oncology Research Group Study 0301. J Clin Oncol 24: 5448-5453, 2006.

20. Murakami H, Yamamoto N, Shibata T, Takeda K, Ichinose Y, Ohe Y, Yamamoto N, Takeda Y, Kudoh S, Atagi S, et al: A single-arm confirmatory study of amrubicin therapy in patients with refractory small-cell lung cancer: Japan Clinical Oncology Group Study (JCOG0901). Lung Cancer 84: 67-72, 2014.

21. Groen HJ, Fokkema E, Biesma B, Kwa B, van Putten JW, Postmus PE and Smit EF: Paclitaxel and carboplatin in the treatment of small-cell lung cancer patients resistant to cyclophosphamide, doxorubicin and etoposide: A non-cross-resistant schedule. J Clin Oncol 17: 927-932, 1999.

22. Iyoda A, Hiroshima K, Moriya Y, Takiguchi Y, Sekine Y, Shibuya K, Iizasa T, Kimura H, Nakatani Y and Fujisawa T: Prospective study of adjuvant chemotherapy for pulmonary large cell neuroendocrine carcinoma. Ann Thorac Surg 82: 1802-1807, 2006.

23. Yamazaki S, Sekine I, Matsuno Y, Takei H, Yamamoto N, Kunitoh H, Ohe Y, Tamura T, Kodama T, Asamura H, et al: Clinical responses of large cell neuroendocrine carcinoma of the lung to cisplatin-based chemotherapy. Lung Cancer 49: 217-223, 2005 